\title{
ELECTROCHEMICAL RECYCLING OF WASTE PRINTED CIRCUIT BOARDS IN BROMIDE MEDIA. PART I: PRELIMINARY LEACHING AND DISMANTLING TESTS
}

\author{
SORIN-AUREL DORNEANU ${ }^{\mathrm{a}}$ *
}

\begin{abstract}
In the context of the large and increasing interest for an efficient and ecological recycling of the Waste Electrical and Electronic Equipments (WEEEs), we decide to evaluate the feasibility of an electrochemical recycling process for waste printed circuit boards (WPCBs) based on bromine-bromide leaching system. For this preliminary study, a perforated rotating drum chemical reactor (RDCR), interconnected with a divided electrochemical reactor (DER) in a closed hydraulic loop, was successfully used to dismantle consecutively three computer motherboards (CMB) after a minimal mechanical pre-treatment. Essentially, the base metals were leached at the RDCR level and the bromine-bromide system was regenerated at the DER level, simultaneously with the partial electrodeposition of dissolved metals. Even if the operating parameters were not optimized, each CMB was completely dismantled in around $18 \mathrm{~h}$, with cathodic and anodic mean current efficiencies of $43.6 \%$ and $58.4 \%$, respectively. Notably, grace to the proposed process, the remaining undissolved parts (fiberglass reinforced epoxy boards, electronic components, plastics, etc.) preserve their original shape and structure, allowing an easier consequent separation-classification and a more efficient and profitable recycling.
\end{abstract}

Keywords: Waste printed circuit boards, metals recovery, electrochemical recycling, bromine-bromide leaching system, environmentally friendly process

\footnotetext{
a Babes-Bolyai University, Faculty of Chemistry and Chemical Engineering, 11 Arany Janos str., RO-400028, Cluj-Napoca, Romania

*Corresponding author: dorneanu@chem.ubbcluj.ro
} 


\section{INTRODUCTION}

At this hour, the quantity of generated WEEEs exceeds $45 \mathrm{Mt} / \mathrm{year}$ and tends to increase with $4 \%$ each year [1]. Moreover, the traditional linear production philosophy ("take-make-dispose") increases resource scarcity, causes great environmental costs and endangers human health. As a solution, the concept of circular economy has been introduced and generally accepted, maximizing the utility and value of components and materials [2]. In this context, for the recycling of WEEEs and, especially, of WPCBs, many researchers have studied and proposed various processes, e.g. physicomechanical [3], hydrometallurgical [4], pyrometallurgical [5], pyrolytic [6] biometallurgical [7] or by combination of thereof as presented in several reviews [8 - 12]. In spite of an intense research activity, proved by the increased number of published papers [13], many of the proposed technologies present serious disadvantages, e.g. extremely low speed for the bioleaching processes and, for the other mentioned processes, high energy and materials consumption, leak of selectivity and generation of toxic or unusable supplementary waste fluxes. The electrochemical recycling of metals from WPCBs represents a feasible alternative and allows the minimization of the drawbacks mentioned before. Several regenerable leaching systems were proposed and tested, e.g. electrogenerated $\mathrm{Cl}_{2}$ in $\mathrm{HCl}$ solution [14], $\mathrm{FeSO}_{4} / \mathrm{H}_{2} \mathrm{SO}_{4}$ [15], $\mathrm{Fe}_{2}\left(\mathrm{SO}_{4}\right)_{3} / \mathrm{H}_{2} \mathrm{SO}_{4}$ [16]. $\mathrm{FeCl}_{3} / \mathrm{HCl}[17-19], \mathrm{SnCl}_{4} / \mathrm{HCl}$ (for solder stripping) [20]. Unfortunately, the electrochemical regeneration of chloride based leaching agents presents the risk of chlorine evolution, requiring well sealed equipments. Also, the presence of sulfate induces a low rate of the solder alloy dissolution if large amounts of $\mathrm{Pb}$ are present. The $\mathrm{Br}_{2}$ based lixiviants can be also used, but some authors suggest that these are unattractive due to the high vapor pressure of $\mathrm{Br}_{2}$ (ex. $28 \mathrm{kPa}$ at $35^{\circ} \mathrm{C}$ ) [21]. Contrarily, other researchers indicate that the use of the adequate complexing agents like bromide or organic ammonium perhalides can resolve this problem [22].

In this context, during the present work, we test the ability of the aqueous $\mathrm{Br}_{2} / \mathrm{KBr}$ leaching system to remove all exposed metallic parts from different models of computer motherboards (CMB), simultaneous with the electrochemical lixiviants regeneration and the partial electrodeposition of the dissolved metals. The experimental setup has included a perforated rotating drum chemical reactor (RDCR) and a divided electrochemical reactor (DER), connected in an electrolyte closed loop. The resulting setup was successfully used for the consecutive dismantling of three different $\mathrm{CMB}$ after a minimal mechanical pre-treatment. Even if the operating parameters were not optimized, each CMB was completely dismantled in around $18 \mathrm{~h}$, with cathodic and anodic mean current efficiencies of $43.6 \%$ and $58.4 \%$, respectively, and a cumulated specific electric energy consumption of $0.65 \mathrm{kWh} / \mathrm{kg}$ of treated WPCB. Finally, it is worth to note that, after the leaching tests, the remaining 
undissolved parts (fiberglass boards, electronic components, plastics, etc.) preserve their original shape and structure, allowing an easier consequent separation/classification and a more efficient recycling.

\section{RESULTS AND DISCUSSION}

Before the leaching experiments, several components were manually removed from the used CMB: the Li batteries, aluminium heat sinks, Cr/Ni plated bronze screws from the peripheral interfaces (RS232, WGA, LPT1, etc.) and the cylindrical aluminium electrolytic capacitors. This minimal mechanical pre-treatment, which lasted less than 2 min. for each $\mathrm{CMB}$, was compulsorily in order to avoid few unwanted problems:

- risk of explosion when the extremely reactive inner of the Li batteries cams in contact with the leaching solution;

- risk of leaching solution contamination with extremely toxic polychloride-biphenyls presented in some cylindrical aluminium electrolytic capacitors;

- increased total time of leaching due to the high thickness of the mentioned screws;

- significant and unjustified consumption of leaching agent for the Al dissolution due to the small commercial value of Al and the difficulty of $\mathrm{Al}$ recovery from the resulting solution. Moreover, the reaction between $\mathrm{Al}$ and the aqueous solutions of bromine generates high amount of gaseous hydrogen and is extremely vigorous and exothermic, increasing the risk of explosion.

After the mechanical pre-treatment of the $\mathrm{CMB}$, the resulted components were weighted separately and each board was broken in few pieces in order to full fit the dimension of the rotating drum from the RDCR. Subsequently, the fragments of the first CMB (model PIII-GA-60XT, designed as CMB1) were introduced in the rotating drum, the RDCR and DER were interconnected and filed with $3.4 \mathrm{~L}$ of $\mathrm{KBr} 2 \mathrm{M}$. Only before the first test (designed as Test1), $38 \mathrm{~mL}$ of liquid bromine and $350 \mathrm{~mL}$ of $\mathrm{HCl}$ (32\%) were added to the leaching solution, resulting concentrations of around $0.25 \mathrm{M}$ and $1 \mathrm{M}$ for bromine and $\mathrm{HCl}$, respectively. In order to allow the reaction between the initial added bromine and the metals from the CMB1, the drum was rotated for $1 \mathrm{~h}$ without the DER energising and the solution was circulated between reactors at a flow rate of $250 \mathrm{~mL} / \mathrm{min}$. During this period, the solution colour change from intense orange to light green, indicating the complete consumption of the initial bromine.

After this preliminary step, we started effectively the Test1, that was divided in 10 successive short experiments, completed at different combinations of current $\left(\mathrm{I}_{\mathrm{WE}}\right)$ and electrolyte flow rate $\left(\mathrm{V}_{\mathrm{F}}\right)$ values, presented in 


\section{S.-A. DORNEANU}

Table 1, where $\mathbf{t}_{\mathrm{START}}, \mathbf{t}_{\mathrm{STOP}}$ and $\mathbf{t}_{\mathrm{NET}}$ represent the experiment starting, ending and net time, respectively, and $\mathrm{S}_{\mathrm{CAT}}$ Stands for the cathode surface. During the measurements, the values of the voltage at the DER terminals $\left(\mathrm{U}_{\mathrm{CELL}}\right)$, working electrode potential $\left(U_{\mathrm{WE}}\right)$, counter-electrode potential $\left(\mathrm{U}_{\mathrm{CE}}\right)$ and $\mathrm{I}_{\mathrm{WE}}$ were recorded, the corresponding concatenated data being presented in Figure 1.

Table 1. Experimental parameters used during Test1

\begin{tabular}{|c|c|c|c|c|c|c|}
\hline Parameter & $\begin{array}{c}\mathbf{t}_{\text {START }} \\
{[\mathbf{m i n}]}\end{array}$ & $\begin{array}{c}\mathbf{t}_{\text {sTOP }} \\
{[\mathbf{m i n}]}\end{array}$ & $\begin{array}{c}\mathbf{t}_{\text {NET }} \\
{[\mathbf{m i n}]}\end{array}$ & $\begin{array}{c}\mathbf{I}_{\text {WE }} \\
{[\mathbf{A}]}\end{array}$ & $\begin{array}{c}\mathbf{V}_{\mathbf{F}} \\
{[\mathbf{m L} / \mathbf{m i n}]}\end{array}$ & $\begin{array}{c}\mathbf{S}_{\text {CAT }} \\
{\left[\mathbf{c m}^{2} \text { ] }\right.}\end{array}$ \\
\hline Test1-Exp.1 & 0 & 50 & 50 & -2.0 & 100 & 298 \\
\hline Test1-Exp.2 & 50 & 200 & 150 & -2.0 & 250 & 298 \\
\hline Test1-Exp.3 & 200 & 339 & 139 & -3.5 & 150 & 192 \\
\hline Test1-Exp.4 & 339 & 403 & 64 & -3.5 & 150 & 192 \\
\hline Test1-Exp.5 & 403 & 439 & 36 & -3.5 & 150 & 192 \\
\hline Test1-Exp.6 & 439 & 477 & 38 & -3.5 & 150 & 192 \\
\hline Test1-Exp.7 & 477 & 601 & 124 & -4.0 & 100 & 192 \\
\hline Test1-Exp.8 & 601 & 746 & 145 & -4.5 & 50 & 192 \\
\hline Test1-Exp.9 & 746 & 847 & 101 & -4.0 & 100 & 192 \\
\hline Test1-Exp.10 & 847 & 1103 & 256 & -4.0 & 25 & 192 \\
\hline
\end{tabular}

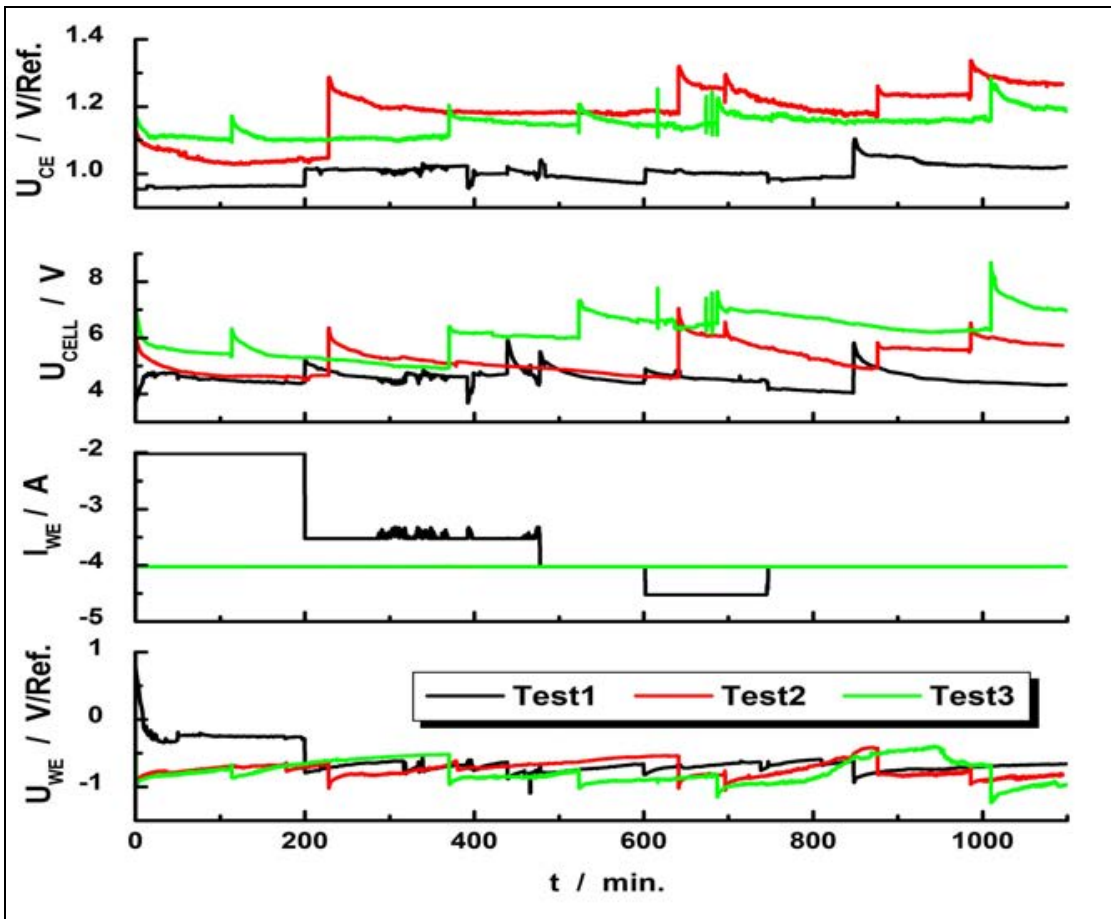

Figure 1. Evolution of the electric parameters recorded at the DER level during the three successive tests of metal leaching using the bromine-bromide system 
Correlating the data from Table 1 and Figure 1 with the visual observation concerning the quality and quantity of the obtained deposits, we conclude that the combination of $I_{W E}=4 \mathrm{~A}$ and $V_{F}=100 \mathrm{~mL} / \mathrm{min}$ represents an acceptable compromise in respect to the electric energy consumption, leaching rate and quantity of the electrodeposited metal. It is worth to note that for all the tested experimental parameters combinations, pulverulent deposits, consisting mainly of $\mathrm{Cu}$, were obtained. After each short experiment, the content of the rotating drum was inspected, revealing that all the accessible thin metallic parts (thickness less than $0.5 \mathrm{~mm}$, e.g. pins, foils, chip terminals, solder points and balls, etc.), were completed dissolved after around 18 hours. The undissolved metallic parts resulted from the CMB1 include only 6 surface mounted MOS-FET power transistors and few pieces of thick enameled cooper wires $(\phi>0.5 \mathrm{~mm})$.

At the end of Test1, the content of the rotating drum was discarded, washed with distilled water, dried, manually sorted and weighted. Also, the pulverulent metal deposit was collected by suction from the DER cathodic compartment, decanted, filtered, washed with distilled water and acetone, fast dried and weighted. In order to evaluate the metallic composition of the obtained deposit, samples of 1-2 g were re-dissolved in aqua regia and analyzed by flame atomic adsorption spectroscopy (FAAS). The final concentrations of the dissolved metals in the leaching solution were also evaluated by FAAS.

Following the protocol described before, other two CMB (both of AMD-DURON - Socket 462 type) were mechanically pre-treated and successively leached using the same electrolyte solution. For Test2 and Test3, identical experimental parameters $\left(I_{\mathrm{WE}}=4 \mathrm{~A}\right.$ and $\left.\mathrm{V}_{\mathrm{F}}=100 \mathrm{~mL} / \mathrm{min}\right)$ were used, the recorded data being also presented in Figure 1.

As can be seen in Figure 1, during the Test2 and Test3, the recorded electrical parameters are similar with those of Test1, with a small increase of the $U_{C E L L}$ and $U_{C E}$. A more accurate comparison can be made base on the calculated mean values, presented in Table 2, where the total consumed electric charge $\left(\mathrm{Q}_{\mathrm{T}}\right)$ and power $\left(\mathrm{W}_{\mathrm{T}}\right)$ values are also included.

Table 2. The averaged values of the electrical parameters recorded during the three successive CMB leaching tests ('Standard deviation)

\begin{tabular}{|l|c|c|c|}
\hline \multicolumn{1}{|c|}{ Parameter } & Test1 & Test2 & Test3 \\
\hline $\mathbf{U}_{\text {WE, MEAN }}[\mathrm{V}]$ & $-0.62 \pm 0.21^{*}$ & $-0.74 \pm 0.11$ & $-0.78 \pm 0.17$ \\
\hline $\mathbf{I}_{\text {WE, MEAN }}[\mathrm{A}]$ & $-3.59 \pm 0.81$ & $-4.02 \pm 10^{-3}$ & $-4.02 \pm 10^{-3}$ \\
\hline $\mathbf{U}_{\text {CELL, MEAN }}[\mathrm{V}]$ & $4.56 \pm 0.26$ & $5.26 \pm 0.49$ & $6.17 \pm 0.69$ \\
\hline $\mathbf{U}_{\text {CE, MEAN }}[\mathrm{V}]$ & $1.01 \pm 0.03$ & $1.18 \pm 0.08$ & $1.15 \pm 0.03$ \\
\hline $\mathbf{Q}_{\mathrm{T}}\left[\mathrm{A}^{*} \mathbf{S}\right]$ & $238^{*} 10^{3}$ & $264^{*} 10^{3}$ & $267^{*} 10^{3}$ \\
\hline $\mathbf{W}_{\mathrm{T}}\left[\mathbf{W}^{*} \mathbf{S}\right]$ & $1.09^{\star} 10^{6}$ & $1.38^{\star} 10^{6}$ & $1.65^{\star} 10^{6}$ \\
\hline
\end{tabular}




\section{S.-A. DORNEANU}

The data from in Table 2 indicate small differences between the averaged values of the electrical parameters recorded during the three successive tests, excerpting $W_{T}$ that increase constantly. This fact suggests that the same solution can be used for repetitive leaching processes.

Based on FAAS analyses, we evaluated, for all three tests, the amount of the electrodeposited $\left(m_{D E P}\right)$ and dissolved $\left(m_{D I S}\right)$ base metals and the current efficiency for the cathodic $\left(r_{f}\right.$, CAT $)$ and anodic ( $r_{f, \text { ANOD }}$ ) processes, the corresponding data being presented in Table 3.

Table 3. Amount (in g) of the electrodeposited and dissolved base metals and the current efficiencies (in \%) for the three successive CMB leaching tests

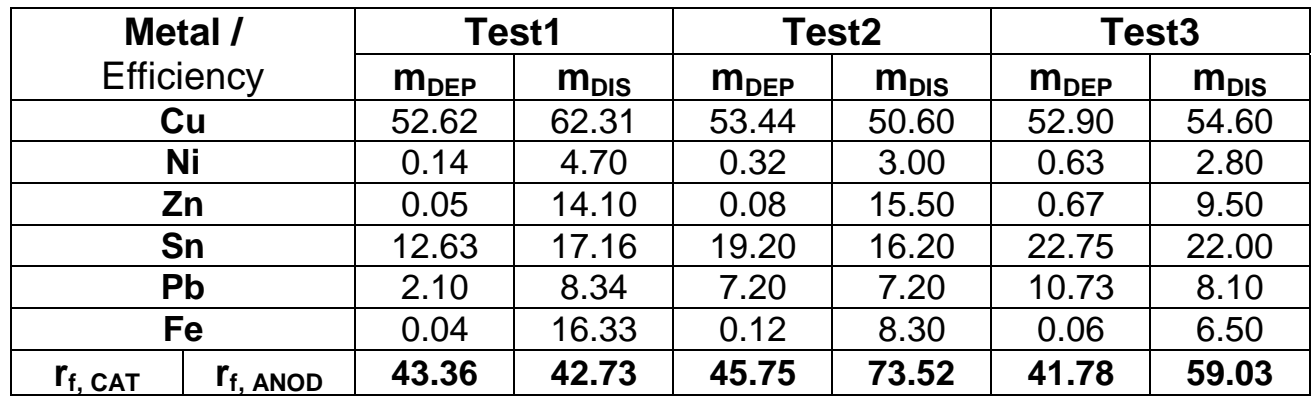

The data presented in Table 3 reveal very important information:

- The great dispersion of the measured $m_{D I S}$ values indicate large differences between the compositions of the leached CMBs.

- For all three tests, the major component of the deposits is $\mathrm{Cu}$ (around $53 \%$ ) and its amount remains quasi-constant, suggesting that this metal can be efficiently recovered by electrodeposition if the operational parameters are optimized.

- The amount of electrodeposited $\mathrm{Sn}$ and $\mathrm{Pb}$ increase constantly, indicating their accumulation in the leaching solution and the necessity of their constant extraction from the electrolyte.

- The quantities of $\mathrm{Ni}, \mathrm{Zn}$ and Fe are extremely small (less than 1\%), suggesting that, using optimal operational parameters, their capture in the $\mathrm{Cu}$ deposits can be eliminated.

- The simple recirculation of the leaching solution on the route RDCR cathodic - anodic induces very low values of the current efficiency, for both $r_{f, C A T}$ and $r_{f, A N O D}$. This fact can be explained by the electrochemical shortcircuit due to the presence of the $\mathrm{Cu}^{+} / \mathrm{Cu}^{2+}, \mathrm{Fe}^{2+} / \mathrm{Fe}^{3+}$ and $\mathrm{Br}_{2} / \mathrm{Br}^{-}$ reversible redox couples on all three compartments. To overcame this drawback, the setup must be re-designed in order to separate the anodic and cathodic fluxes. 
Based on the cumulated $m_{D E P}, m_{D I S}$ values and amounts of parts separated mechanically for all three tests, we elaborated the mass balance and the flowchart of the global process, presented in Figure 2.

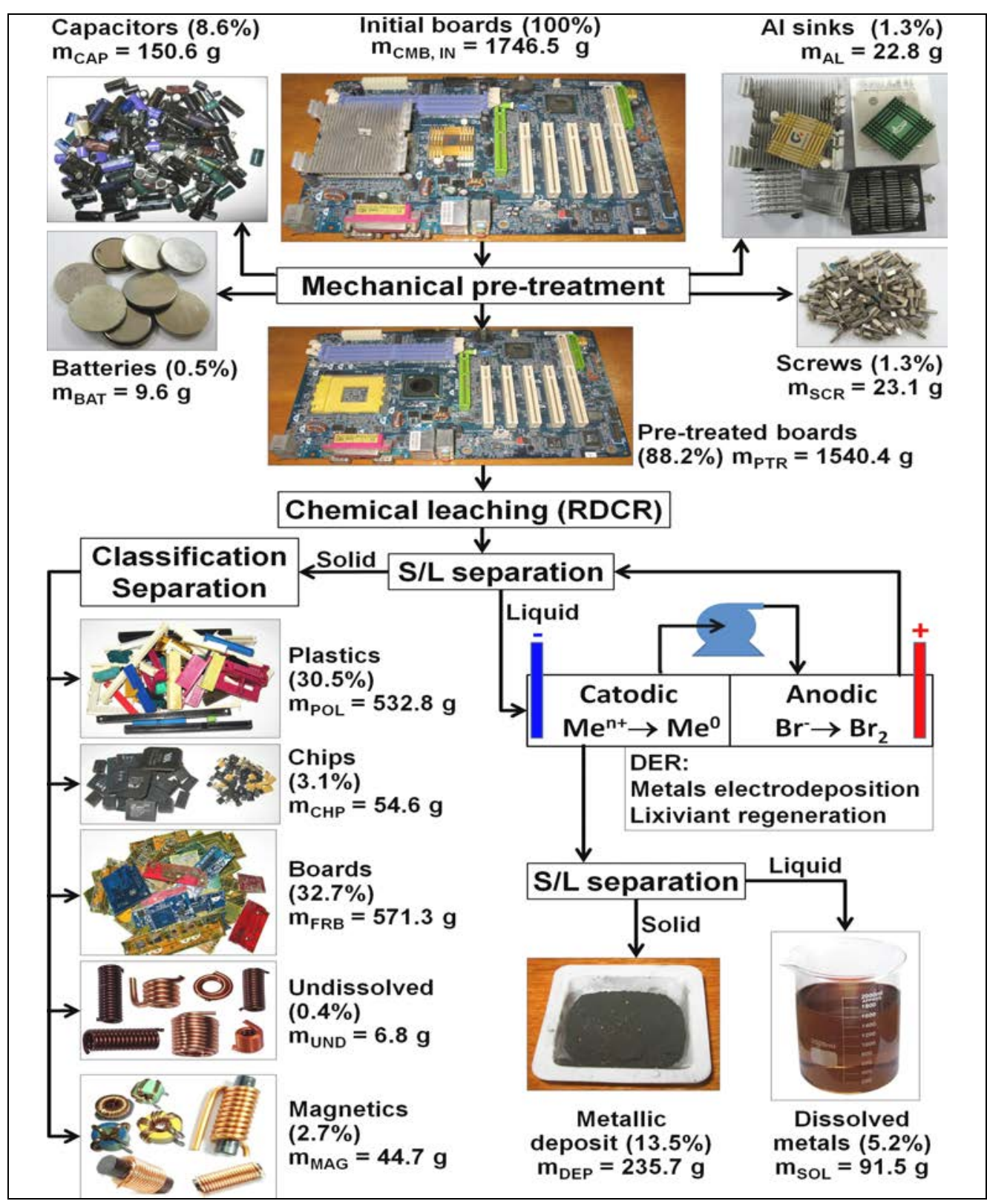

Figure 2. Mass balance and flowchart of the global dismantling process 


\section{S.-A. DORNEANU}

For Figure 2, the designed names, corresponding weight symbols and compositions of the resulted fractions after the mechanical pretreatment and leaching steps are summarized in Table 4.

Table 4. Designed names, weight symbols and compositions of separated fractions from CMB by mechanical pre-treatment and leaching

\begin{tabular}{|l|c|l|}
\hline $\begin{array}{c}\text { Fractions } \\
\text { designed names }\end{array}$ & $\begin{array}{c}\text { Weight } \\
\text { symbol }\end{array}$ & \multicolumn{1}{|c|}{ Composition of the fractions } \\
\hline Initial boards & $\mathbf{m}_{\mathrm{CMB}, \mathrm{IN}}$ & Untreated boards with all components \\
\hline Batteries & $\mathbf{m}_{\mathrm{BAT}}$ & Button cell Li-batteries for CMBs clock \\
\hline Al sinks & $\mathbf{m}_{\mathrm{AL}}$ & Aluminium heat sinks \\
\hline Capacitors & $\mathbf{m}_{\mathrm{CAP}}$ & Al based cylindrical electrolytic capacitors \\
\hline Screws & $\mathbf{m}_{\mathrm{SCR}}$ & Ni/Cr plated screws from peripheral connectors \\
\hline Pre-treated boards & $\mathbf{m}_{\mathrm{PTR}}$ & Mechanically pre-treated CMBs \\
\hline Boards & $\mathbf{m}_{\mathrm{FRB}}$ & Fiberglass reinforced epoxy boards \\
\hline Magnetics & $\mathbf{m}_{\mathrm{MAG}}$ & Ferrite or iron coil cores, CPU locking levers \\
\hline Plastics & $\mathbf{m}_{\mathrm{POL}}$ & Polymer based extruded/injected parts \\
\hline Chips & $\mathbf{m}_{\mathrm{CHP}}$ & $\begin{array}{l}\text { Electronic chips and small surface mounting devices (SMD), } \\
\text { all without terminals }\end{array}$ \\
\hline Undissolved & $\mathbf{m}_{\mathrm{UND}}$ & $\begin{array}{l}\text { Undissolved metallic parts like high power SMD-MOS- } \\
\text { FETs and thick enameled cooper wires }\end{array}$ \\
\hline Dissolved metals & $\mathbf{m}_{\mathrm{SOL}}$ & Dissolved metals remained in lixiviant \\
\hline
\end{tabular}

The mass balance presented in Figure 2 indicate that the direct leachable metals represents $18.7 \%$ from the total weight of CMBs and, for the used operational parameters, at least $72 \%$ from the dissolved base metals can be recovered by electrodeposition in one stage.

Finally, based on the cumulated values of $\mathrm{W}_{\mathrm{T}}, \mathrm{m}_{\mathrm{DIS}}$ and $\mathrm{m}_{\mathrm{CMB}, \mathrm{IN}}$ (see Table 2 and Figure 2), the global specific electricity consumptions were calculated, values of 0.65 and $3.5 \mathrm{kWh} / \mathrm{kg}$ being obtained in respect to the mass of treated CMBs and recoverable metals, respectively. Taking into account the market value of the leached base metals, the composition of the deposits and the price of electric energy, we conclude that the expenses for the consumed electricity during the leaching process can be covered by the value of the recovered base metals. In this conditions, the high value of the precious metals presented on the CMB, neglected during this study, can increase significantly the process profitability.

\section{CONCLUSIONS}

The main conclusion of the present study consists in the certitude that the electrochemical regenerable $\mathrm{Br}_{2} / \mathrm{Br}^{-}$leaching system can be successfully 
used for the dismantling of WPCBs and the recovery of the base metals from wasted CMBs. The proposed process requires only a minimal mechanical pretreatment. and its profitability can be increased significantly by recovering and valorising the precious metals from the WPCBs.

Finally, it is very important to note that the proposed and tested process allows to preserve the original shape and structure of the remaining undissolved parts (fiberglass boards, electronic components, plastics, etc.), facilitating a more easier and profitable classification, separation and recycling of these secondary waste fluxes.

\section{EXPERIMENTAL SECTION}

The leaching tests were performed in a RDCR made from HD-PP, the volume of the drum and reactor being of 1.5 and $3 \mathrm{~L}$, respectively. The DER, of rectangular shape, was constructed also from HD-PP, divided in two chambers by a ceramic porous membrane. A peristaltic pump (model TC, Medorex, Germany) was used to transfer the electrolyte from the cathodic to the anodic compartment of DER. Both DER compartments were connected with RDCR following the principle of communicating vessels, assuring an uniform circulation of the electrolyte in the whole. system. The anode was a rectangular graphite block $\left(H^{*} W * D=80 * 70 * 20 \mathrm{~cm}^{3}\right)$, immersed $6.5 \mathrm{~cm}$ in solution. The "brush" shape cathode consisted in 30 or 20 cylindrical bares of spectral graphite $(\phi=0.5 \mathrm{~cm}, \mathrm{H}=10 \mathrm{~cm})$, immersed $6 \mathrm{~cm}$ in solution. The $U_{W E}$ and $U_{C E}$ were measured and reported in respect to two reference electrode of $\mathrm{Ag} / \mathrm{AgCl} / \mathrm{KCl}_{\text {SAT }}$ type $(\varepsilon=+0.197 \mathrm{~V} / \mathrm{SHE})$.

Before the Test1, the reactors were filed with $3.5 \mathrm{~L}$ of solution containing $2 \mathrm{M} \mathrm{KB}, 0.25 \mathrm{M} \mathrm{Br}_{2}$ and $0.2 \mathrm{M} \mathrm{HCl}$ that was reused during Test2 and Test3. A computer controlled P/G-stat (model DXC236, Datronix Computers, Romania) was used to impose the current through DER and measure the resulting potentials. A data acquisition board (model PCI-6221M, National Instruments, USA) and dedicated LabView 2015 (National Instruments, USA) applications were used to control the P/G-stat operation and acquire data. The FAAS analyses were performed using an AVANTA-PM spectrometer (GBS, Australia) in air/acetylene flame mode. The weights of the initial CMBs and all the other separated fraction were measured using a laboratory electronic balance (model PLJ-510-3m, KERN\&SOHN GmbH, Germany).

\section{ACKNOWLEDGMENTS}

The author would like to acknowledge to Florica Imre-Lucaci and Vasile Coman for their help concerning the FAAS analyses and mass balance evaluation, respectively. 


\section{S.-A. DORNEANU}

\section{REFERENCES}

1. B. Tansel, Environment International, 2017, 98, 35.

2. L. Cong, F. Zhao, J. W. Sutherland, Journal of Cleaner Production, 2017, 149, 378.

3. M. Kaya, "Recovery of Metals and Nonmetals from Waste Printed Circuit Boards (PCBs) by Physical Recycling Techniques" in Energy Technology 2017, The Minerals, Metals \& Materials Series, Springer, Chambrige, 2017, 433-451.

4. E. M. Iannicelli-Zubiani, M. I. Giani, F. Recanati, G. Dotelli, S. Puricelli, C. Cristiani, Journal of Cleaner Production, 2017, 140, 1204.

5. M. Ghodrat, M. A. Rhamdhani, A. Khaliq, G. Brooks, B. Samali, Journal of Material Cycles and Waste Management, 2017, 1.

6. C. Zhao, X. Zhang, L. Shi, Waste Management, 2017, 61, 354.

7. A. Priya S. Hait, Environmental Science and Pollution Research, 2017, 24(8), 6989.

8. A. Chatterjee, J. Abraham, International Journal of Environmental Science and Technology, 2017, 14(1), 211.

9. A. Kumar, M. Holuszko, D. C. R. Espinosa, Resources, Conservation and Recycling, 2017, 122, 32.

10. F. Tesfaye, D. Lindberg, J. Hamuyuni, P. Taskinen, L. Hupa, Minerals Engineering, 2017, 111, 209.

11. M. Wang, Q. Tan, J. F. Chiang, Frontiers of Environmental Science \& Engineering, 2017, 11(5), 1.

12. T. Oki, T. Suzuki, "The Advanced Recycling Technology for Realizing Urban Mines Contributing to Climate Change Mitigation" in Handbook of Climate Change Mitigation and Adaptation, Springer International Publishing Switzerland, 2017, 1007-1035.

13. G. Cecere, A. Martinelli, Research Policy, 2017, vol. 46(5), 925,.

14. E. Y. Kim, M. S. Kim, J. C. Lee, J. Jeong, B. D. Pandey, Hydrometallurgy, 2011, 107(3-4), 124.

15. T. E. Lister, P. Wang, A. Anderko, Hydrometallurgy, 2014, 149, 228.

16. L. A. Diaz, T. E. Lister, J. A. Parkman, G. G. Clark, Journal of Cleaner Production, 2016, 125, 236.

17. S. Fogarasi, F. Imre-Lucaci, P. Ilea, Á. Imre-Lucaci, Journal of Cleaner Production, 2013, 54, 264.

18. S. Fogarasi, F. Imre-Lucaci, Á. Imre-Lucaci, P. Ilea, Journal of Hazardous Materials, 2014, 273, 215.

19. S. Fogarasi, F. Imre-Lucaci, A. Egedy, Á. Imre-Lucaci, P. Ilea, Waste Management, 2015, 40, 136.

20. Y. Jian-guang, L. Jie, P. Si-yao, L. Yuan-lu, Journal of Hazardous Materials, 2016, 304, 409.

21. Y. Zhang, S. Liu, H. Xie, X. Zeng, J. Li, Procedia Environmental Sciences, vol. 2012, 16, 560.

22. C. N. Mpinga, J. J. Eksteen, C. Aldrich, L. Dyer, Minerals Engineering, 2015, $78,93$. 